\title{
Newcastle: "If it doesn't work here, it can't work anywhere"
}

\author{
Jane Smith
}

Newcastle upon Tyne, a city of 273000 people and regional capital of the north east, starts off with several advantages for community care. ${ }^{1}$ Some are structural - the health authority, family health services authority, and local authority are coterminous-while others stem from tradition and a strong sense of community. Despite the familiar fears about the implementation of community care-not enough money, buck passing, and bed blocking-I was struck by the optimism of social services staff. Even so, there's a clear split between the planners and the practitioners: the former see the new framework as strengthening existing good professional relationships; the practitioners, in the health service particularly, fear it as a layer of bureaucracy that may undermine those relationships.

\section{Longstanding good relationships}

Newcastle's Labour council has long had a policy of supporting its community-a policy that has informed many aspects of city life. Thus the underground transport system, the Metro, was built with disabled people in mind and council residential homes buy all their supplies locally, to support their communities. The council spends heavily on social services, partly as a general policy and partly to provide targeted services to vulnerable groups. Brian Roycroft, director of social services, is clearly proud of the standards of city provision and its responsiveness to users and carers.

Roycroft also claims-and many in the health authority agree with him - that relationships between the social services department and the health authority, both managerially and professionally, have long been good and have helped underpin a high level of community care. ${ }^{2}$ Hence his belief that if community care can't work in Newcastle "it can't work anywhere."

\section{Implementing community care}

Possibly because of this widespread feeling that relationships between health and social services were good, planning for April 1993 got left behind, and the city has spent the past few months frantically catching up. "If you had asked me a year ago," said Roycroft, "I'd have said everything was going wonderfully well-but then it all fell apart." The main problem was rate capping for the city council, which meant that the social services department had to save $£ 4 \mathrm{~m}$ and lose 400 staff. Homes for the elderly were shut, and, formerly nominal charges increased and extended. Three of the four people on the community care implementation team left. At the same time the chairman and chief executive of the Newcastle Health Authority left amidst acrimony about restructuring within the Northern region.

Realising that things were getting behind, Roycroft pulled together a policy group consisting of himself, Gary Smith, and Clare Dodgson (chief executives of the health authority and the family health services authority). Soon afterwards the chairman of the local medical committee, Dr Frankie Walters, joined the group-a move that many in Newcastle think important both symbolically and practically.

\section{The community care plan}

The core work on client groups for the 1993 community care plan is being done by the six joint care planning teams (covering aging, physical disability, learning difficulties, mental health, HIV/AIDS, and drug and alcohol problems). These have representatives of the independent sector, users and carers, ethnic minorities, and the housing department as well as social services, family health services authority, and health authority members. Although the teams have an important role in constructing the plan, they have tended to be marginalised because they control few resources. As John Harvey, director of public health, put it, many of the teams take a very global view for their client group, consult widely, come up with good ideas, and are responsive to users, but their influence is tiny. "They have become forums for airing aspirations."

Harvey would like to see them bound more closely into the decision making process. As an example he cites a review that the health authority and the mental health trust have just completed of their mental health strategy, using the planning team as an important part of the consultation mechanism. One of the recommendations is that the planning team should implement the review by analysing different ways of providing particular services - crisis intervention, for example - and making recommendations to the purchasing authority.

\section{The purchaser-provider split}

To implement a purchaser-provider split within Newcastle social services department the plan is to let the fieldwork section, based in area social work teams, act as purchasers and the residential and day care section (which includes home care) to act as providers. Few people in the department see this split as being very real at the moment, particularly as it will be some time before budgets are devolved. Roycroft doesn't particularly like the idea; he thinks assessment and provision go together for individuals $-a$ view shared by most of his social workers.

Meanwhile the problem for the health service is that although the health authority sits on the policy group and is a coauthor of the community care plan, the work gets done-and the problems arise-in provider units. Both Gary Smith and Barry Dowdeswell, chief executive of the Royal Victoria Infirmary, Newcastle's oldest teaching hospital, agreed that the acute hospitals had only just woken up to community care. Only now are they starting to organise training for their staff. As a result, said Dowdeswell, they had realised how lucky they were with their hospital social workers: "The hospital teams have been very well protected within social services."

Nevertheless, there are fears. Roycroft and Smith worry about perverse incentives: the fact that hospital treatment costs nothing, while people have to pay for the home care that will keep them out

\section{London WC1H 9JR}

Jane Smith, deputy editor

BMF 1993;306:566-9 


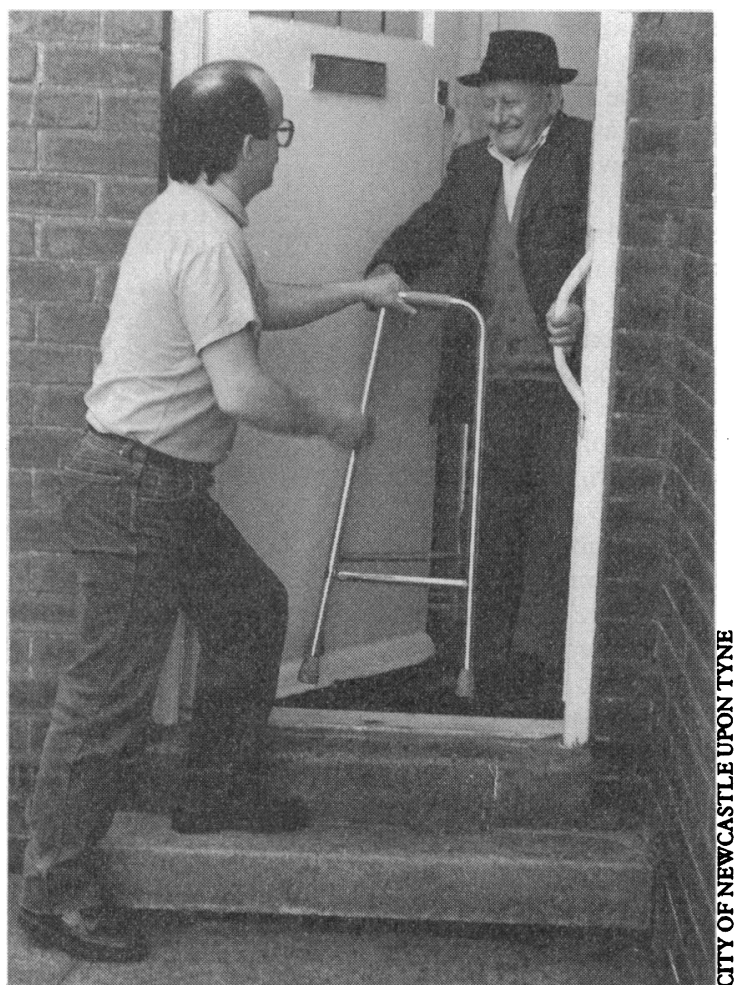

The "real backbone" of Newcastle's social services: home care. .

of hospital. Dowdeswell worries about meeting contract commitments and the costs of having a geriatrician concerned in all complex assessments in elderly people. Doctors and nurses worry about bed blocking.

\section{Within the hospital}

Nurses at the infirmary have just been praised by the Audit Commission for their work on discharge planning, and a group of sisters in the orthopaedic unit confirmed that they had long taken this seriously. They discuss any problem cases with their hospital social worker each week, occupational therapists routinely make home visits before discharge, and if minor adaptations are needed a hospital technician will do them. Nevertheless, there are delays in discharge at the moment, often caused by silly things like a lack of commodes, and the nurses worry that if everything has to be in place before discharge then there will be more delays. But the blame is always with the system, not the individuals: "We're lucky with our social worker-she works wonders," said one of the sisters.

The strongest criticism I heard came from $\mathrm{Dr}$ Alistair Brewis, consultant chest physician and medical director of the Royal Victoria Infirmary. Not realising that the documents on discharge and assessment had been produced in a hurry to meet the government's suddenly imposed deadline of 31 December, he criticised the two weeks he had been given to consult his 200 consultant colleagues. "The act is all about communications - but here's a bad way of communicating at the outset." He found it difficult to get consultants interested in community care because it was only one on a long list of issues. Terry Sangwin, the nurse manager for the medical unit, thought staff in the hospital still needed much more information about what would happen, and she feared the planners didn't realise the impact community care might have on acute hospitals. Both she and Dr Brewis were also concerned about the many patients on their wards who came from outside Newcastle: they knew even less about the arrangements for community care within those districts.
Jackie Marston, manager of the hospital social workers, was still negotiating funding for social work links with these surrounding districts when I met her and some of her team at the hospital. They were very positive about community care and saw it as natural development of their work. Marsden explained that hospital social workers had negotiated their role in discharge in the 1970s, when the Freeman Hospital had been built-"discharges don't happen without social services input"- and had then spread the same working practices to Newcastle's other two acute hospitals.

They were very aware of the fears about bed blocking. Indeed, they had just finished a three month study, half funded by the hospital "at a time when it didn't have a penny" to assess bed blocking on one medical/geriatric ward that had particular problems. The delays were caused mainly by patients waiting for long term care (because private provision hadn't kept up with demand). As a result Anne Wilson, the ward's social worker, is now funded half by the hospital to work at the Sanderson rehabilitation centre to liaise with community social workers and families.

Anne Wilson and her colleagues were as concerned as anyone that assessments are done promptly. "Not delaying assessment and placement is important to the user and family - it maintains their confidence." They too mentioned things like delays in supplying commodes that currently kept patients waiting. All these examples, they thought, simply highlighted the need for better coordination.

Indeed, Kate Weightman, programme director at the community health unit, thought that the planning envisaged by the community care plan would actually speed throughput by instilling the need to plan discharge from the outset of a hospital episode-and before when possible. Her unit is already used to joint working with social services. It manages the joint inspection unit for nursing and residential homes and runs the joint loan equipment service (the one that never has enough commodes). She is also running awareness training in community care which brings together community health staff, general practice nurses, and social workers, and her district nurses already provide some joint training for their own auxiliaries and social service home carers.

\section{Assessment}

The fear about bed blocking is acknowledged in Newcastle's assessment procedures, which speak repeatedly about the need not to delay discharge. Three levels of assessment are envisaged, and most people think that only the last of these-a complex assessment-will be new. The first level is simply to provide people with information on services - through hospitals, general practitioners' surgeries, social services offices, and public libraries. Anyone can then request an initial assessment of needs, which will be provided if the person falls into one of the client groups (elderly; mentally ill; with learning disabilities; with physical or sensory disability or chronic illness; with drug or alcohol problems; or at risk of infection with HIV) and is experiencing difficulty with daily living.

Carolyn Stephenson, principal assistant (community care) in the social services department, doesn't think any of this is different from what staff do already. People may, for example, be referred by general practitioners, who would be expected to provide any relevant information. In future any referrer will have to provide an agreed minimum data set. Moreover, "if a person has been assessed by a general practitioner or a nurse for health reasons and they have identified social needs at the same time then we are committed to accepting that assessment," said Stephenson. She said 
that some social workers were uneasy about that, and she agreed that it involved trust, but it was also to avoid abandoning the problem to someone else. What is also new, she emphasised, is that the assessment is of a need, not for a particular service. It will then be up to a care manager to decide on the level of service.

This will probably involve a social worker in an area team putting together a package that might consist of a few hours of home care, a couple of days of day care, and night sitting for one night. "Probably these people don't need a formal care manager, though someone will be responsible for them," says Stephenson.

The impact of the new legislation will be felt most for people who have complex needs identified as a result of a comprehensive assessment. The key criteria are that a person has a range of needs that cannot be met by one agency alone and his or her ability to live independently is in jeopardy. This is the level where care managers will come into their own, thinks Stephenson. They need not always be social workers, and indeed, there is one care management pilot going on in the city that has a district nurse as a care manager. Here too, eventually, is where there will be budgets for care.

\section{Budgets and services}

But what will those budgets buy? Before the allocations were known the social services department had worked out that ideally it would need $£ 5.75 \mathrm{~m}$. It has got $£ 3.2 \mathrm{~m}$. Already some social services have long waiting lists because demand outstrips supply. Nevertheless, Graham Armstrong, assistant director of social services responsible for finance and administration and now leading the community care project team, is more worried about the second and third years. Ninety per cent of people in residential care in Newcastle are on income support and the average time to death or discharge in residential care is three years, so his department will be picking up the whole burden by the third year. The main shift as he sees it is that the service has become cash limited overnight. "So we have to get the eligibility criteria tied down very tight. Yet if you establish criteria for nursing and residential care you are adjusting to resources, not need."

In the first year Armstrong's concern is to go for a minimum safe agenda - "make sure clients are safe and then build on that." He has not therefore got very far with devolving budgets. In 1993 they will be allocated to area managers but not yet to care managers. This fits in with the traditionally tight control that local authority finance directors like to keep. Armstrong's other concern is that budgets should be tightly tied to the

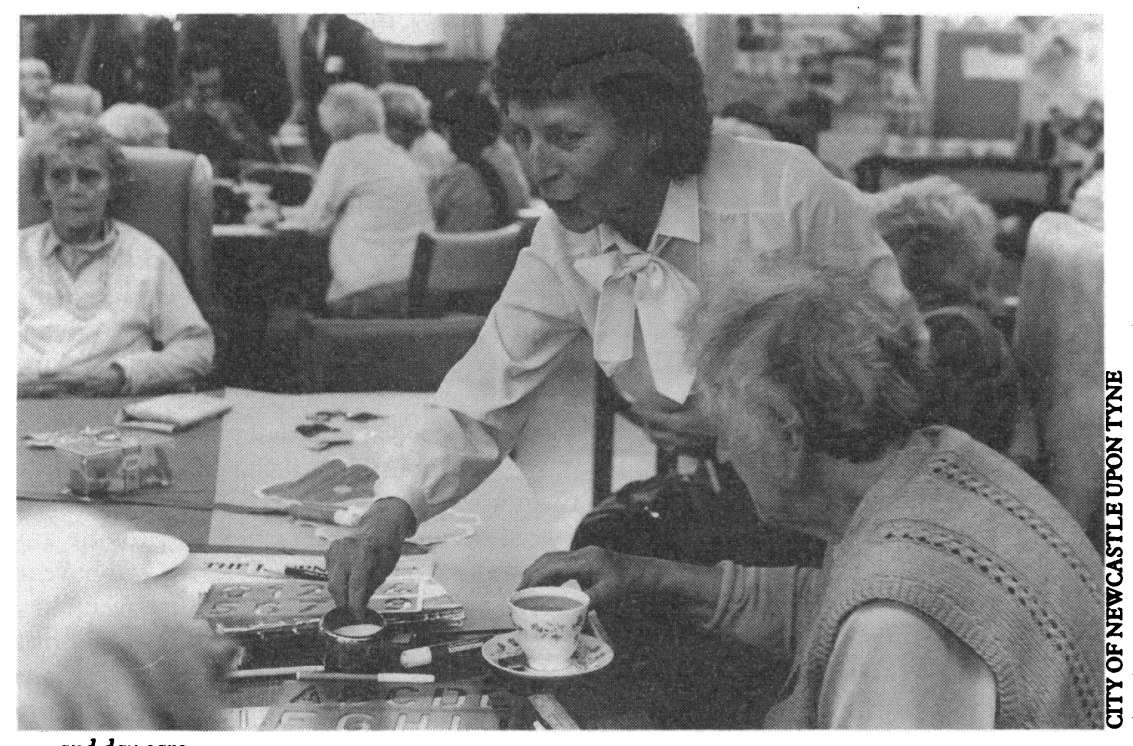

. and day care

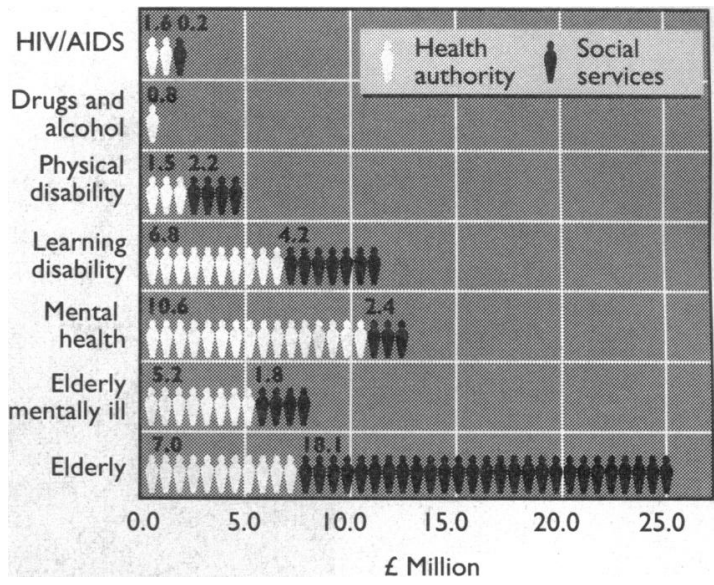

Expenditure on social and continuing health care services in Newcastle in 1991-2 by health authority and social services

information strategy, and his department is not far advanced with that.

Another concern is to ensure that new sorts of responsive services are there to meet identified needs. As well as managing the market the social services department is having to nurture it. Stephenson thinks that unless there are no informal carers (in which case providing continuous support at home is much more expensive than residential care) much can be done to keep even very dependent people at home. But first those services need to exist. A night sitting service, for example, needs a certain number of permanent trained staff. "So there will have to be some block contracts to provide predictability for the provider," says Stephenson. Likewise, voluntary bodies need funding to enable them to bid for contracts. The department had hoped to reach flexible service agreements with many voluntary bodies, but the city's lawyers told them they either had to give grants (guaranteeing nothing in return) or set binding contracts.

\section{Care management}

Legal problems have also dogged some innovative experiments within the care management pilots the city is running. Lynn Boyle, a social worker from area 2, told how the Inland Revenue had scuppered a plan to get unemployed women to provide informal care in return for expenses and small payments. The tax authorities insisted they put the women on the payroll.

Like her boss, Boyle doesn't see why assessment and care management should be separated. She sees assessments as involving a dialogue with the client, with social workers sometimes doing therapeutic work as part of the process. She thought enforcing a distinction would simply become bureaucratic. She also told of how social workers could stimulate resources very locally. Her area has many people with learning disabilities; the community is tolerant and the housing stock suits conversion. Both the housing department and housing associations had helped with accommodation, and the social work team had started luncheon clubs and drop in centres for people with learning disabilities who did not go to day centres. They then persuaded user groups, voluntary bodies, and churches to take these services over.

Boyle also spoke of her colleagues' traditionally mixed views about general practitioners. Whether much good would come out of closer formal links between social workers and general practices very much depended on the general practitioners' attitude.

"GPs don't understand what we do"-they referred inappropriate patients, and were often reluctant to pass on information. She also conceded, however, "We tend not routinely to inform GPs. There isn't a sense 


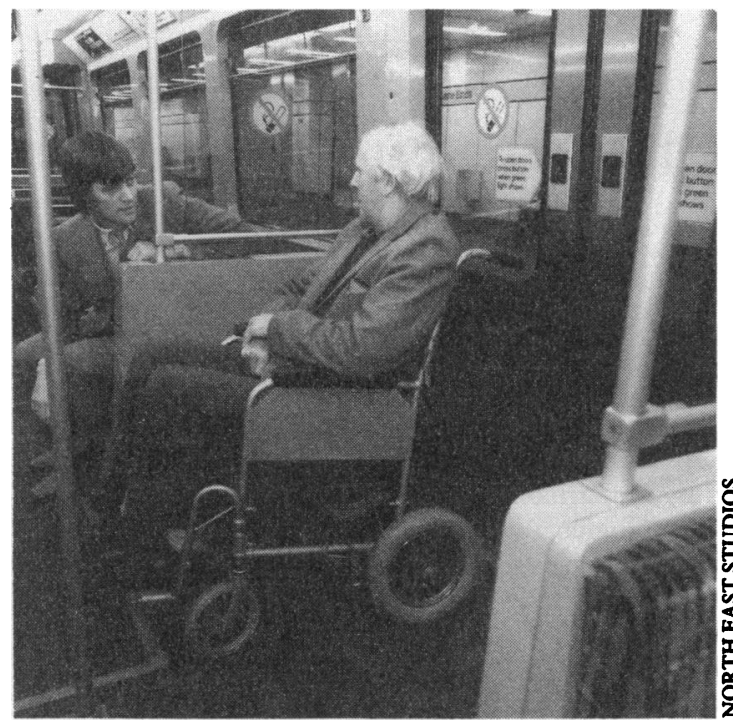

The Metro, a symbol of Newcastle's commitment to supplying people in the community

of coresponsibility, and we need to change that."

When the two groups do work together the outcome is better. Boyle cited a recent example of an elderly woman who was being physically abused. The doctor had helped assess the problem because she had a good relationship with her patient and had documented all her injuries. Another case in which good relationships would have helped was that of an attention seeking woman who had spent most of her life in hostels and was constantly getting struck off general practitioners' lists. "It would have been nice to have worked through the issues with the GPs and negotiated with the patient."

\section{General practitioners}

Dr Frankie Walters, chairman of the local medical committee and a general practitioner in west Newcastle, agrees with Boyle's analysis that relationships between general practitioners and social workers have not always been good. She too is optimistic that they are changing: "We are learning to talk much more openly without scoring points." As a result of her involvement in the policy group all 46 practices in Newcastle were consulted over the draft discharge and assessment arrangements and had an opportunity to influence them. The family health services authority has funded Walters' locum costs ("14 meetings in two months") and the costs of training for general practitioners and their staff, and Brian Roycroft came and spoke to well attended meetings of fundholders and non-fundholders. One thing he did was to reassure them that planning was not as far advanced as they had feared. Nevertheless, most general practitioners remain concerned about the lack of detail in the assessment and discharge documents - and are waiting to see the more detailed information that is promised before April. They also worry that assessment procedures will raise expectations that can't be met.

Walters knows well enough not to promise to deliver for general practitioners. "The most I can do is say, 'This is what GPs are thinking'." Also, both she and Clare Dodgson, chief executive of the family health services authority, worry that, despite the well attended meetings, there are still some general practitioners who know nothing about community care. "If they don't know by 1 April, it won't be through want of trying," says Walters.

That so much effort has gone into getting general practitioners on board is a tribute to the widely held view within social services that general practitioners are not central to community care, but their capacity for throwing a spanner in the works is considerable. Yet both Clare Dodgson and John Harvey, director of public health, see beyond that.

Dodgson thinks that the debate over community care has brought out a demand among general practitioners for attached social workers, particularly among fundholders. Harvey also sees general practitioners as having a key role in the information strategy for community care. Despite the firm figures in the community care plan (see table), and social services managers' confidence that they know the level of need in the city, he thinks they know little. "Need is not a static concept: we need a longitudinal view and to understand how needs change." He wants to know, for example, the risk among 100 people aged over 80 of any of them needing care over the next five years-because a carer dies, they have a stroke, or they develop dementia. As part of a locality purchasing project in the east end of the city he is working with several practices to see how general practitioners can provide this sort of information.

Need in Newcastle - from 1992 community care plan

\begin{tabular}{lr}
\hline & $\begin{array}{r}\text { No of people } \\
\text { affected }\end{array}$ \\
\hline $\begin{array}{l}\text { Broad needs } \\
\text { Continuing ill health }\end{array}$ & 90000 \\
Age $\geqslant 85$ & 4900 \\
Carers & 30200 \\
Low income & 52000 \\
Discrimination (ethnic minorities) & 7000 \\
Vulnerable groups & \\
Severe learning disabilities requiring continuing care & 1000 \\
Mental illness requiring continuing care & 1000 \\
Homeless mentally ill & 300 \\
HIV infection & 100 \\
Alcohol or drug problems & 1400 \\
Severe sensory or physical disability requiring care & 800 \\
Carers providing $>20 \mathrm{~h}$ of care a week & 6500 \\
\hline
\end{tabular}

\section{The future}

The locality purchasing project also raises questions about joint purchasing. Everyone agrees that if the service is to be seamless there are enormous benefits in having people providing care across the health-social care boundary - "one person providing bathing, bandaging, and hoovering"- and not bothering about who pays. But there are huge political difficulties with the latter. "Councillors are not going to give up their responsibility for how money is spent," says Roycroft. Themselves accountable to an electorate, councillors are sceptical about the accountability of health authorities-and about health authorities' knowledge of the community: to them it's simply what happens outside hospital. Nevertheless, most of the planners in Newcastle think that the issue of joint purchasing and a wider debate about dissolving the boundary between health markets and care markets is one that the community care arrangements will increasingly force upon them.

But all that is some way off, and not confined to Newcastle. For the time being Brian Roycroft assures everyone that they won't fall off a precipice on 1 April and that community care is going to work. Although Newcastle is having to run very hard to catch up with the mechanics of community care, Roycroft thinks that in terms of the spirit of the act, the city is already way ahead. "On things like consulting with patients and carers-we've been doing that for years."

1 Secretaries of State for Health, Social Security, Wales, and Scotland. Caring for people: commenity care in the next decade and beyond. London: HMSO, 1989.

2 Parmership in action: a study of existing prooision of care facilities and services for physically handicapped and frail elderly people in Newcastle. London: Business Sciences, 1989. 